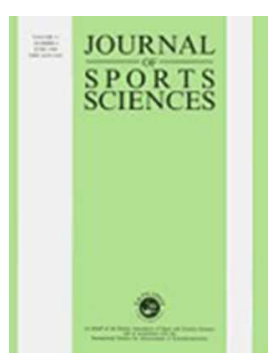

\title{
AGREEMENT BETWEEN BIOELECTRICAL IMPEDANCE AND DUAL ENERGY X-RAY ABSORPTIOMETRY IN ASSESSING FAT, LEAN AND BONE MASS CHANGES IN ADULTS AFTER A LIFESTYLE INTERVENTION
}

\begin{tabular}{|r|l|}
\hline Journal: & Journal of Sports Sciences \\
\hline Manuscript ID & RJSP-2014-1134.R3 \\
\hline Manuscript Type: & Original Manuscript \\
\hline Keywords: & fat mass, lean mass, agreement, intervention \\
\hline \multicolumn{2}{|l}{} \\
\hline
\end{tabular}

SCHOLARONE ${ }^{\mathrm{IM}}$

Manuscripts 


\begin{abstract}
(word count $=200 ;<200$ limit)
\end{abstract}
We aimed to assess the agreement of a commercially available bioelectrical impedance analysis (BIA) device in measuring changes in fat, lean and bone mass over a 10-week lifestyle intervention, with dual energy X-ray absorptiometry (DXA) as reference. A sample of 136 volunteers (18-66 yr) underwent a physical activity intervention to enhance lean mass and reduce fat mass. BIA (Tanita BC545) and DXA (Hologic Explorer) measures of whole body composition were taken at baseline and the end of the intervention. After an average of $74 \pm 18$ days intervention, DXA showed significant changes in 2 of 3 outcome variables: reduced fat mass of $0.802 \pm 1.092 \mathrm{~kg}(\mathrm{p}<0.001)$, increased lean mass of $0.477 \pm 0.966 \mathrm{~kg}(\mathrm{p}<0.001)$; minor non-significant increase of $0.007 \pm 0.041 \mathrm{~kg}$ of bone mass $(\mathrm{p}=0.052)$. The respective changes in BIA measures were a significant reduction of $0.486 \pm 1.539 \mathrm{~kg}$ fat $(\mathrm{p}<0.001)$, but non-significant increases of $0.084 \pm 1.201 \mathrm{~kg}$ lean mass $(\mathrm{p}=0.425)$, and $0.014 \pm 0.091 \mathrm{~kg}$ bone $(\mathrm{p}=0.074)$. Significant, but moderately weak, correlations were seen in absolute mass changes between DXA and BIA: 0.511 (fat), 0.362 (lean), and 0.172 (bone). Compared to DXA, the BIA demonstrated mediocre agreement to changes in fat mass, but poor agreement to lean mass changes. BIA significantly underestimated the magnitude of changes in fat and lean mass compared to DXA.

Keywords: fat mass, lean mass, agreement, intervention

Main body word count $<3300$ words (lower than 4000 limit). 


\section{Introduction}

It is widely accepted that increasing levels of obesity places considerable stress not only on the overweight/obese individuals, but also on public health expenditures. Nutritional and physical activity interventions provide the potential to mitigate some of the negative consequences of poor lifestyle habits. Monitoring changes only in body mass fails to provide the more detailed feedback on body composition that is often recommended (Thomson, Brinkworth, Buckley, Noakes, \& Clifton, 2007). Advanced measurement of body composition using dual-energy X-ray absorptiometry (DXA) provides detailed analyses that are considered both valid and reliable, to the extent of being a reference method for body composition comparison (Anderson, Erceg, \& Schroeder, 2012; Bosy-Westphal et al., 2008). However, DXA has several limitations, including: it is not routinely accessible since it requires a substantial capital outlay; it requires trained operators; it is not portable for field assessments; and it exposes participants to a very mild dose of ionizing radiation. Hence, use of such equipment is counter to the behavioural intervention theories which often suggest methods to facilitate motivation and enhance compliance that include self-monitoring strategies (Michie, Johnston, Francis, Hardeman, \& Eccles, 2008). For adequately powered field studies, the use of relatively inexpensive, simple and accurate methods that can be used to monitor changes in body composition, especially fat and lean mass, and using a real-world scenario rather than a highly-controlled laboratory setting, would be more appropriate.

Consumer-based bioelectric impedance analysis (BIA) devices have become increasingly popular for self-monitoring of body composition as they are often affordable, portable, safe, and require no training (Kyle, Bosaeus, De Lorenzo, URL: http://mc.manuscriptcentral.com/rjsp 
Deurenberg, Elia, Gomez, et al., 2004; Kyle, Bosaeus, De Lorenzo, Deurenberg, Elia, Manuel Gomez, et al., 2004). Although studies often report extremely high levels of reliability for a range of BIA devices (Macfarlane, 2007), there is less agreement on their criterion validity. When compared to DXA, some crosssectional studies using healthy adults have shown acceptable levels of validity using single-frequency (Demura, Sato, \& Kitabayashi, 2004), and multifrequency devices (Anderson et al., 2012; Sun et al., 2005), yet others report less favourable comparisons (Andreoli et al., 2002).

Although BIA devices may show significant bias compared to DXA in crosssectional studies, it is important to be able to find widely available methods that can accurately monitor changes in body composition at the individual level during physical activity and/or dietary interventions. Simple mass scales only monitor changes in mass during lifestyle interventions, but will not vary if an individual loses $2 \mathrm{~kg}$ of fat whilst gaining $2 \mathrm{~kg}$ of lean mass. Despite attaining positive changes in body composition, the zero change in body mass may sufficiently demotivate the individual to discontinue the lifestyle intervention. Consequently, improved self-monitoring methods would help consumers more accurately monitor their body composition changes during lifestyle interventions.

A relatively small number of similar studies have examined whether single and/or multi-frequency BIA devices can accurately monitor changes in body composition during weight loss programmes, although most focus on overweight/obese or clinical patients (Jebb et al., 2007; Li et al., 2013; Miyatani, Yang, Thomas, Craven, \& Oh, 2012; Pietiläinen et al., 2013; Thomson et al., 2007; Verdich et al., 2011). These studies report inconsistent findings; most reported URL: http://mc.manuscriptcentral.com/rjsp 
BIA accurately monitoring changes over time compared to DXA, but some (Verdich et al., 2011) suggested the large individual errors limit BIA to monitoring changes at the group level only. Even fewer studies have examined longitudinal changes in body composition on normal-weight healthy individuals.

Whilst BIA is routinely used to estimate fat mass, it also has the advantage of being the only widely available and simple electronic predictive method that estimates lean mass (Böhm \& Heitmann, 2013; Wells \& Fewtrell, 2006), and indeed can estimate muscle mass accurately compared with DXA (Bosaeus, Wilcox, Rothenberg, \& Strauss, 2013). More recently, BIA has also been used to develop predictive equations to estimate bone mineral content (Patil, Patkar, Mandlik, Kuswarkar, \& Jindal, 2012). Yet to our best knowledge, no field study to date has examined the ability of recently-developed portable dual frequency BIA to monitor changes in fat mass, lean mass and bone mass over a training programme in a mixed group of predominantly normal-weight healthy adults. Based on studies cited earlier, it was hypothesized that compared to the reference DXA, the Tanita BIA would adequately monitor qualitative changes (a gain or loss) in fat mass and lean mass only, but be less sensitive in monitoring quantitative changes in body composition at the individual level.

\section{Methods}

Participants: A sample of 136 adults aged 18-66 years volunteered (42 males, 94 females; mean age 44yr, SD = 12), with their baseline anthropometric characteristics shown in Table 1. The participants were all recruited through the "Exercise for Life" program within the Active Health Clinic at the University of Hong Kong, and were predominantly university staff members or family members. All participants completed a health history questionnaire, the PAR-Q, 
and signed an informed consent form; the study was approved by the Human Research Ethics Committee for Non-clinical Faculties at the University of Hong Kong.

Protocol: The Exercise for Life program was designed to be a 10-week "realworld" lifestyle/fitness intervention aimed at enhancing metabolic health, with expected reductions in fat mass and improvements in lean mass. An exercise program was individually tailored for each participant and monitored by a qualified exercise specialist. Each person participated in a supervised exercise class 3 days per week, beginning with a range of health-related measurements at baseline that included stature (to nearest $\mathrm{mm}$, Seca stadiometer), mass (to nearest $0.1 \mathrm{~kg}$, Tanita BC545N), and body composition using both BIA and DXA. These measurements were repeated at the end of the intervention period using the same standardized procedures.

Bioelectrical Impedance Analysis (BIA): The BIA machine was the portable Tanita Innerscan BC545N (Tanita Corp, Tokyo). This uses 10 electrodes (3 under each foot, and two in each hand using a retractable handle), with a dualfrequency analysis at $6.25 \mathrm{kHz}$ and $50 \mathrm{kHz}$ (Knechtle et al., 2010), to provide estimates of total (and segmental) lean mass, fat mass and bone mass. Participants were asked to refrain from vigorous physical activity, or consuming food, alcohol or diuretic fluids for 4 hours beforehand, to be normally hydrated and were invited to void the bladder and bowels immediately prior to measurement. Each participant wore minimal clothing, had their gender, age and stature entered into the device, then stood on the device with bare feet and grasped the retractable handle according to the manufacturer's 
recommendations. All BIA results were immediately recorded manually by the experimenter.

DXA: A full body DXA scanner (Explorer S/N 91075, Hologic Inc., Waltham, USA) was used to measure body composition and to report total lean mass, fat mass and bone mass. For the purpose of this study, DXA was considered the reference measure. Trained and ISCD-certified DXA technicians performed all DXA scans according to the manufacturer's guidelines in operating the machine, positioning the participants and to analysing the results. For the facility used in this study, typical coefficients of variation for each body compartment from duplicate analyses are $0.4 \%$ for lean mass, $1.4 \%$ for fat mass, and $1.0 \%$ for bone mass.

Statistical Analysis: The variables of lean mass, fat mass, and bone mass were compared for both the BIA and the DXA using a within-method analysis (pre v post), and also a between-method analysis (BIA v DXA) via paired T-tests with statistical significance determined when $\mathrm{p}<0.05$, as well as Bland-Altman analyses (Bland \& Altman, 1986). Percentage changes after intervention, their limits of agreement (LOA), along with Cohen effect sizes (d) were also calculated with small, medium and large effects defined as around $0.2,0.5$ and 0.8 respectively (Cohen, 1988). Analyses were conducted using MedCalc statistical software (MedCalc Software, Ostend, Belgium).

$$
<\text { Table } 1 \text { near here > }
$$

\section{Results}

As shown in Table 2 over the 10 weeks of the lifestyle intervention the participants on average reduced their total body mass by $313 \mathrm{~g}(-0.5 \%)$, which 
was statistically significant $(t=2.43, p=0.008)$, although a small effect size (0.20). The $0.802 \mathrm{~kg}$ reduction in fat mass measured by the DXA was significant $(\mathrm{t}=8.53, \mathrm{p}<0.001)$, and $\mathrm{a}-3.7 \%$ loss of fat mass, which was statistically larger $(\mathrm{t}$ $=3.072, \mathrm{p}=0.003$ ) than the significant $0.486 \mathrm{~kg}$ reduction in fat mass measured by the Tanita BIA $(t=3.68, p<0.001)$, with effect size changes being small $(<0.20)$. The reduction in fat mass measured by the BIA represented just over half $(60.5 \%)$ of the fat loss measured by the reference DXA, and represented a substantial effect size difference of 0.72 . The difference between the fat loss assessed by BIA and DXA is also shown in the Bland-Altman graph (Fig 1), which depicts a systematic error (with a mean bias of $0.32 \mathrm{~kg}$; LoA $-2.39-3.03$ ) that is proportional to the size of the measured value, with the random errors relatively uniform. The mean bias of $0.32 \mathrm{~kg}$ shows the BIA typically underestimated the fat mass loss. In terms of the qualitative/directional agreement, BIA only agreed $70 \%$ of the time with the directional (gain v loss of fat) when compared to DXA.

$<$ Table 2 near here >

Over the intervention the DXA monitored a statistically significant mean gain of $0.477 \mathrm{~kg}$ of lean mass $(\mathrm{t}=-5.77, \mathrm{p}<0.001)$, representing a $0.3 \%$ gain in lean mass, which was not statistically different $(t=0.86, p=0.392)$ compared to the nonsignificant mean gain of $0.084 \mathrm{~kg}$ measured by BIA; effect size changes in lean mass were both trivial $(<0.1)$. The increase in lean mass measured by the BIA represented only $17.6 \%$ of the lean mass gain measured by the reference DXA, with the effect size difference being substantial (0.79). The Bland-Altman graph (Fig 2) depicts a systematic error (with a mean bias of $-0.39 \mathrm{~kg}$; LoA $2.05--2.84$ ) that is again proportional to the size of the measured value, with the random errors relatively uniform. The mean bias of $-0.39 \mathrm{~kg}$ indicating the BIA typically URL: http://mc.manuscriptcentral.com/rjsp 
underestimated the lean mass gained. The BIA again only agreed $70 \%$ of the time with qualitative/directional (gain v loss of lean mass) when compared to DXA.

$<$ Figure 1 near here $>$

Not un-expectantly, changes in bone mass were minor, with trivial effect sizes. The DXA monitored a statistically non-significant mean gain of $0.007 \mathrm{~kg}$ of bone tissue $(t=-1.96, p=0.052)$, representing a $0.3 \%$ gain in bone mass, which was not statistically different $(t=0.86, p=0.392)$, than the non-significant mean gain of $0.014 \mathrm{~kg}$ measured by BIA. Despite this, a large effect size (0.93) was reported for the difference between the DXA v BIA changes. When compared to DXA, BIA correctly agreed the direction of the bone changes (gain v loss) only $58 \%$ of the time.

$<$ Figure 2 near here $>$

Table 2 also shows significant, but moderate, Spearman correlations were seen in absolute mass changes between DXA and BIA of 0.511 (fat), 0.362 (lean), whilst the correlation for bone of 0.172 was weak, but remained just statistically significant $(\mathrm{p}=0.047)$.

\section{Discussion}

It is very helpful for not only health professionals but also motivated members of the community to be able to objectively assess aspects of body composition using relatively inexpensive and widely available consumer products. The ability of BIA devices to accurately monitor changes in body composition are of primary URL: http://mc.manuscriptcentral.com/rjsp 
importance in many studies rather than their cross-sectional validity (Jebb et al., 2007). This "real-world" study presents novel data to show that when compared to the reference device (DXA), a commonly available consumer BIA device (Tanita Innerscan BC545N) is unable to accurately monitor changes in fat and lean mass over a lifestyle intervention lasting 10 weeks. Compared to the reference DXA, the Tanita only assessed $61 \%$ and $18 \%$ of the respective mean quantitative changes in fat and lean mass. Whilst the within-device effect sizes for change-scores for fat and lean mass were similar between BIA and DXA (small or trivial changes respectively), the between-device comparisons showed poor agreement, with moderately weak correlations for fat and lean tissue (0.511 and 0.362) and large effect size for the differences (0.72-0.79).

A range of other BIA devices have been recently investigated to determine their ability to monitor changes in body composition over a lifestyle intervention, including Omron (Pietiläinen et al., 2013), InBody (Sillanpaa, Hakkinen, \& Hakkinen, 2013), ImpiMed (Bosaeus et al., 2013; Moon et al., 2013; Thomson et al., 2007), BodyStat (Verdich et al., 2011); RJL systems (Aslam et al., 2009). Since comparing BIA devices of different manufacturers is not the focus of this study, although an overview is available (Jaffrin, 2009), subsequent commentary will be predominantly restricted to the performance of Tanita BIA devices.

Various Tanita BIA devices have been used to monitor changes in body composition, predominantly on clinically-related patients aiming at fat loss. The Tanita 305 was reasonably accurate in monitoring fat and lean mass loss in overweight participants, but underestimated lean mass loss (BIA -1.6kg v DXA $1.9 \mathrm{~kg}$ ) and overestimated fat loss. (BIA $-5.2 \mathrm{~kg}$ v DXA $-4.8 \mathrm{~kg}$ ) (Frisard, Greenway, \& Delany, 2005), whilst it accurately monitored changes in fat mass in obese URL: http://mc.manuscriptcentral.com/rjsp 
females (Jebb et al., 2007) The Tanita Ultimate Scale 2000 reasonably assessed changes in fat and lean mass loss in overweight young women compared to DXA, but under-reported fat loss and over-reported lean tissue loss (Thomson et al., 2007). Recently the Tanita TBF-300A was considered acceptable for qualitative assessment of body changes in diabetic patients, but not sensitive enough to monitor quantitative changes in an individual (Miyatani et al., 2012). In 2013 the Tanita BC-418 was used on a sample of Taiwanese overweight/obese patients during a $6 \mathrm{mo}$ weight loss intervention and significantly underestimated body fat loss compared to DXA, showing greater error in those with higher body fat (Li et al., 2013).

To date we are not aware of published work examining a dual-frequency Tanita BIA to assess changes in fat, lean mass, and potentially bone, using apparently healthy male and female individuals and over an intervention aimed at reducing fat and increasing lean mass. The results demonstrate that the BC-545N significantly under-reported the mean losses in body fat (the Tanita only reported $60.5 \%$ of the fat loss determined via DXA), and also grossly underreported the mean increase in lean mass (the Tanita reported less than $18 \%$ of the lean mass gain determined via DXA). Changes in bone mass determined both by DXA and BIA were, as predicted, trivial and of no practical significance, other than to demonstrate they could be monitored using BIA with some degree of accuracy (i.e., agreement of no change) when compared to the reference DXA. The efficacy of using BIA to monitor changes in bone mass longitudinally remains an area of potential research, especially for countries without routine access to DXA technology. 
Although the moderately weak correlations between absolute changes in mass over the intervention for fat and lean tissue show that the BC545N provides some useful qualitative (directional) information about these changes in body composition (70\% accuracy of a gain $\mathrm{v}$ loss), the BIA is not adequately sensitive to monitor the magnitude (quantitative changes) of body composition variation in these individuals. This is supported by the Bland-Altman plots (Figure 1 and 2): despite relatively small mean bias in changes in fat and lean mass between the BIA and DXA of around $0.3 \mathrm{~kg}$, the relatively wide LOA lines show a much wider range variation is possible for individual scores. This suggests the BC545N was not sufficiently sensitive in monitoring changes in fat and lean mass when compared to DXA (error differences often beyond $2 \mathrm{~kg}$ ) and hence this BIA device needs to be interpreted with considerable caution when examining changes at the individual level. These findings are very similar to that of Miyantani et al. who used the single-frequency Tanita TBF-300A leg-to-leg device on diabetic patients (Miyatani et al., 2012).

The change-score LOA's from Table 2 are also considerably larger than the mean change reported by the BIA or DXA and are in line with the change-score effect sizes in suggesting the absolute changes seen over this short intervention were of small or trivial practical significance. However, statistically these changes were unlikely to have happened via chance alone, and for many individuals losing an average of $0.8 \mathrm{~kg}$ of fat mass and gaining nearly $0.5 \mathrm{~kg}$ of lean tissue (as determined via DXA) is likely to have been an important, rewarding, and healthenhancing event. Yet the BC545N would typically not have been able to adequately reflect the magnitude of these changes at the individual level. 
The strengths of this study was the examination of whether, compared to a DXA reference, the consumer-oriented BC545N could monitor changes in body composition over a short-term intervention using a respectable number $(n=136)$ of apparently healthy individuals (many of whom were ethnic Chinese, a group that has been understudied via BIA); it also used an intervention that targeted not only fat loss but also lean mass gain. There are several clear limitations. Both DXA and BIA measurements are sensitive to hydration levels and food intake, and all participants were asked to attend in a state of normal hydration and standard conditions (no prior exercise nor food in the previous 4 hours; void bowels and bladder, same time of day, etc.), but this $4 \mathrm{hr}$ period was not a long as a 8-12hr fast used in some highly controlled laboratory studies as we felt this longer fast would have significantly compromised compliance within our "lifestyle study". Thus, some daily variations in hydration/digestion are possible, but likely to have been random and affected both devices simultaneously as the DXA and BIA scans were taken only a few minutes apart for each individual, thus the important change-score would not have been differentially affected. The intervention only lasted a relatively short 10 weeks, however, this still permitted statistically significant changes in both fat and lean mass, although these changes were of low clinical importance. As the participants did not follow a unified/consistent dose of exercise, considerable heterogeneity/variability in the responses (fat and lean mass change) was expected and this possibly inflated the LOA values. DXA is not a sufficiently adequate criterion method, but it is only a common reference (Bilsborough et al., 2014; Kyle, Bosaeus, De Lorenzo, Deurenberg, Elia, Gomez, et al., 2004; Miyatani et al., 2012), and since not all measurements were taken by a single technician, but rather by qualified densitometrists using a standardized protocol, some variations in analysis might occur. Although BIA is predominantly used to estimate body water and fat mass, 
it is also now regarded as being suitable to assess lean mass (Böhm \& Heitmann, 2013; Bosaeus et al., 2013; Janssen, Heymsfield, Baumgartner, \& Ross, 2000), and recently also used to predict bone mass in developing nations (Ekbote, Khadilkar, Chiplonkar, Mughal, \& Khadilkar, 2013; Patil et al., 2012), yet further work remains to further validate its use in predicting bone mass.

\section{Conclusions}

Changes in whole body fat following a lifestyle intervention only showed mediocre agreement using the Tanita BC545N BIA device, with $61 \%$ of the mean quantitative change determined by DXA being detected and $70 \%$ accuracy in the qualitative changes (gain v loss). However, this BIA device showed poor agreement in changes in lean mass, with less than $18 \%$ of the mean quantitative changes detected, even though $70 \%$ of the qualitative changes (gain v loss) agreed with DXA. Insufficient changes in bone mass occurred to allow any firm conclusions to be made. Overall, the Tanita BC545N BIA significantly underestimated the magnitude of changes in both fat and lean mass compared to DXA, with effect sizes of these changes being greater than 0.7 .

\section{References}

Anderson, L. J., Erceg, D. N., \& Schroeder, E. T. (2012). Utility of multifrequency bioelectrical impedance compared with dual-energy x-ray absorptiometry for assessment of total and regional body composition varies between men and women. Nutrition Research, 32(7), 479-485. doi: 10.1016/j.nutres.2012.05.009

Andreoli, A., Melchiorri, G., De Lorenzo, A., Caruso, I., Sinibaldi Salimei, P., \& Guerrisi, M. (2002). Bioelectrical impedance measures in different position and vs dual-energy X-ray absorptiometry (DXA). Journal of Sports Medicine and Physical Fitness, 42(2), 186-189.

Aslam, M., Eckhauser, A. W., Dorminy, C. A., Dossett, C. M., Choi, L., \& Buchowski, M. S. (2009). Assessing Body Fat Changes during Moderate Weight Loss with Anthropometry and Bioelectrical Impedance. Obesity Research \& Clinical Practice, 3(4), 209. doi: 10.1016/j.orcp.2009.03.005

Bilsborough, J. C., Greenway, K., Opar, D., Livingstone, S., Cordy, J., \& Coutts, A. J. (2014). The accuracy and precision of DXA for assessing body 
composition in team sport athletes. Journal of Sports Sciences, 32(19), 1821-1828. doi: Doi 10.1080/02640414.2014.926380

Bland, J. M., \& Altman, D. G. (1986). Statistical methods for assessing agreement between two methods of clinical measurement. Lancet, 327, 307-310.

Böhm, A., \& Heitmann, B. (2013). The use of bioelectrical impedance analysis for body composition in epidemiological studies. European Journal of Clinical Nutrition, 67, S79-S85.

Bosaeus, I., Wilcox, G., Rothenberg, E., \& Strauss, B. J. (2013). Skeletal muscle mass in hospitalized elderly patients: Comparison of measurements by single-frequency BIA and DXA. Clinical Nutrition, 33(3), 426-431.

Bosy-Westphal, A., Later, W., Hitze, B., Sato, T., Kossel, E., Gluer, C. C., . . . Muller, M. J. (2008). Accuracy of bioelectrical impedance consumer devices for measurement of body composition in comparison to whole body magnetic resonance imaging and dual X-ray absorptiometry. Obesity Facts, 1(6), 319-324. doi: 10.1159/000176061

Cohen, J. (1988). Statistical power analysis for the behavioural sciences (2 ed.). New Jersey: Lawrence Elrbaum.

Demura, S., Sato, S., \& Kitabayashi, T. (2004). Percentage of total body fat as estimated by three automatic bioelectrical impedance analyzers. Journal of Physiological Anthropology and Applied Human Science, 23(3), 93-99.

Ekbote, V., Khadilkar, A., Chiplonkar, S., Mughal, M. Z., \& Khadilkar, V. (2013). Bioelectrical impedance as a screening tool for low bone mass in Indian children and adolescents. Bone Abstracts, 2, 50.

Frisard, M. I., Greenway, F. L., \& Delany, J. P. (2005). Comparison of methods to assess body composition changes during a period of weight loss. Obesity Research, 13(5), 845-854. doi: 10.1038/oby.2005.97

Jaffrin, M. Y. (2009). Body composition determination by bioimpedance: an update. Current Opinion in Clinical Nutrition \& Metabolic Care, 12(5), 482486.

Janssen, I., Heymsfield, S. B., Baumgartner, R. N., \& Ross, R. (2000). Estimation of skeletal muscle mass by bioelectrical impedance analysis. Journal of Applied Physiology, 89(2), 465-471.

Jebb, S., Siervo, M., Murgatroyd, P., Evans, S., Frühbeck, G., \& Prentice, A. (2007). Validity of the leg-to-leg bioimpedance to estimate changes in body fat during weight loss and regain in overweight women: a comparison with multi-compartment models. International Journal of Obesity, 31(5), 756762.

Knechtle, B., Wirth, A., Baumann, B., Knechtle, P., Kohler, G., Rosemann, T., \& Senn, O. (2010). An ironman triathlon does not lead to a change in body mass in female triathletes. Research in Sports Medicine, 18(2), 115-126.

Kyle, U. G., Bosaeus, I., De Lorenzo, A. D., Deurenberg, P., Elia, M., Gomez, J. M., . . Composition of the, E. W. G. (2004). Bioelectrical impedance analysis-part I: review of principles and methods. Clinical Nutrition, 23(5), 12261243. doi: 10.1016/j.clnu.2004.06.004

Kyle, U. G., Bosaeus, I., De Lorenzo, A. D., Deurenberg, P., Elia, M., Manuel Gomez, J.,... Espen. (2004). Bioelectrical impedance analysis-part II: utilization in clinical practice. Clinical Nutrition, 23(6), 1430-1453. doi: 10.1016/j.clnu.2004.09.012

Li, Y. C., Li, C. I., Lin, W. Y., Liu, C. S., Hsu, H. S., Lee, C. C., . . Lin, C. C. (2013). Percentage of body fat assessment using bioelectrical impedance analysis and dual-energy X-ray absorptiometry in a weight loss program for obese or overweight Chinese adults. PLoS One, 8(4), e58272. doi: 10.1371/journal.pone.0058272 
Macfarlane, D. J. (2007). Can bioelectric impedance monitors be used to accurately estimate body fat in Chinese adults? Asia Pacific Journal of Clinical Nutrition, 16(1), 66-73.

Michie, S., Johnston, M., Francis, J., Hardeman, W., \& Eccles, M. (2008). From theory to intervention: Mapping theoretically derived behavioural determinants to behaviour change techniques. Applied Psychology-an International Review-Psychologie Appliquee-Revue Internationale, 57(4), 660-680. doi: Doi 10.1111/J.1464-0597.2008.00341.X

Miyatani, M., Yang, P., Thomas, S., Craven, B. C., \& Oh, P. (2012). Bioelectrical impedance and dual-energy $\mathrm{x}$-ray absorptiometry assessments of changes in body composition following exercise in patients with type 2 diabetes mellitus. Journal of Obesity, 2012, 953060. doi: 10.1155/2012/953060

Moon, J. R., Stout, J. R., Smith-Ryan, A. E., Kendall, K. L., Fukuda, D. H., Cramer, J. T., \& Moon, S. E. (2013). Tracking fat-free mass changes in elderly men and women using single-frequency bioimpedance and dual-energy X-ray absorptiometry: a four-compartment model comparison. European Journal of Clinical Nutrition, 67, S40-S46. doi: Doi 10.1038/Ejcn.2012.163

Patil, B., Patkar, D., Mandlik, S., Kuswarkar, M., \& Jindal, G. (2012). Estimation of bone mineral content from bioelectrical impedance analysis in Indian adults aged 23-81 years: a comparison with dual energy X-ray absorptiometry. International Journal of Biomedical Engineering and Technology, 8(1), 99-114.

Pietiläinen, K., Kaye, S., Karmi, A., Suojanen, L., Rissanen, A., \& Virtanen, K. (2013). Agreement of bioelectrical impedance with dual-energy X-ray absorptiometry and MRI to estimate changes in body fat, skeletal muscle and visceral fat during a 12-month weight loss intervention. The British journal of nutrition, 109, 1910-1916.

Sillanpaa, E., Hakkinen, A., \& Hakkinen, K. (2013). Body composition changes by DXA, BIA and skinfolds during exercise training in women. European Journal of Applied Physiology, 113(9), 2331-2341. doi: 10.1007/s00421013-2669-9

Sun, G., French, C. R., Martin, G. R., Younghusband, B., Green, R. C., Xie, Y. G., . . Zhang, H. (2005). Comparison of multifrequency bioelectrical impedance analysis with dual-energy X-ray absorptiometry for assessment of percentage body fat in a large, healthy population. American Journal of Clinical Nutrition, 81(1), 74-78.

Thomson, R., Brinkworth, G. D., Buckley, J. D., Noakes, M., \& Clifton, P. M. (2007). Good agreement between bioelectrical impedance and dual-energy X-ray absorptiometry for estimating changes in body composition during weight loss in overweight young women. Clinical Nutrition, 26(6), 771777.

Verdich, C., Barbe, P., Petersen, M., Grau, K., Ward, L., Macdonald, I., ... Oppert, J.M. (2011). Changes in body composition during weight loss in obese subjects in the NUGENOB study: Comparison of bioelectrical impedance vs. dual-energy X-ray absorptiometry. Diabetes and Metabolism, 37(3), 222-229.

Wells, J. C., \& Fewtrell, M. S. (2006). Measuring body composition. Archives of Disease in Childhood, 91(7), 612-617. doi: 10.1136/adc.2005.085522 
Figure 1. Bland-Altman plot of fat change-score comparing the mean of Dual-energy X-ray absorptiometry (DXA) and Bioelectrical Impedance Analysis (BIA) against the difference between BIA and DXA.

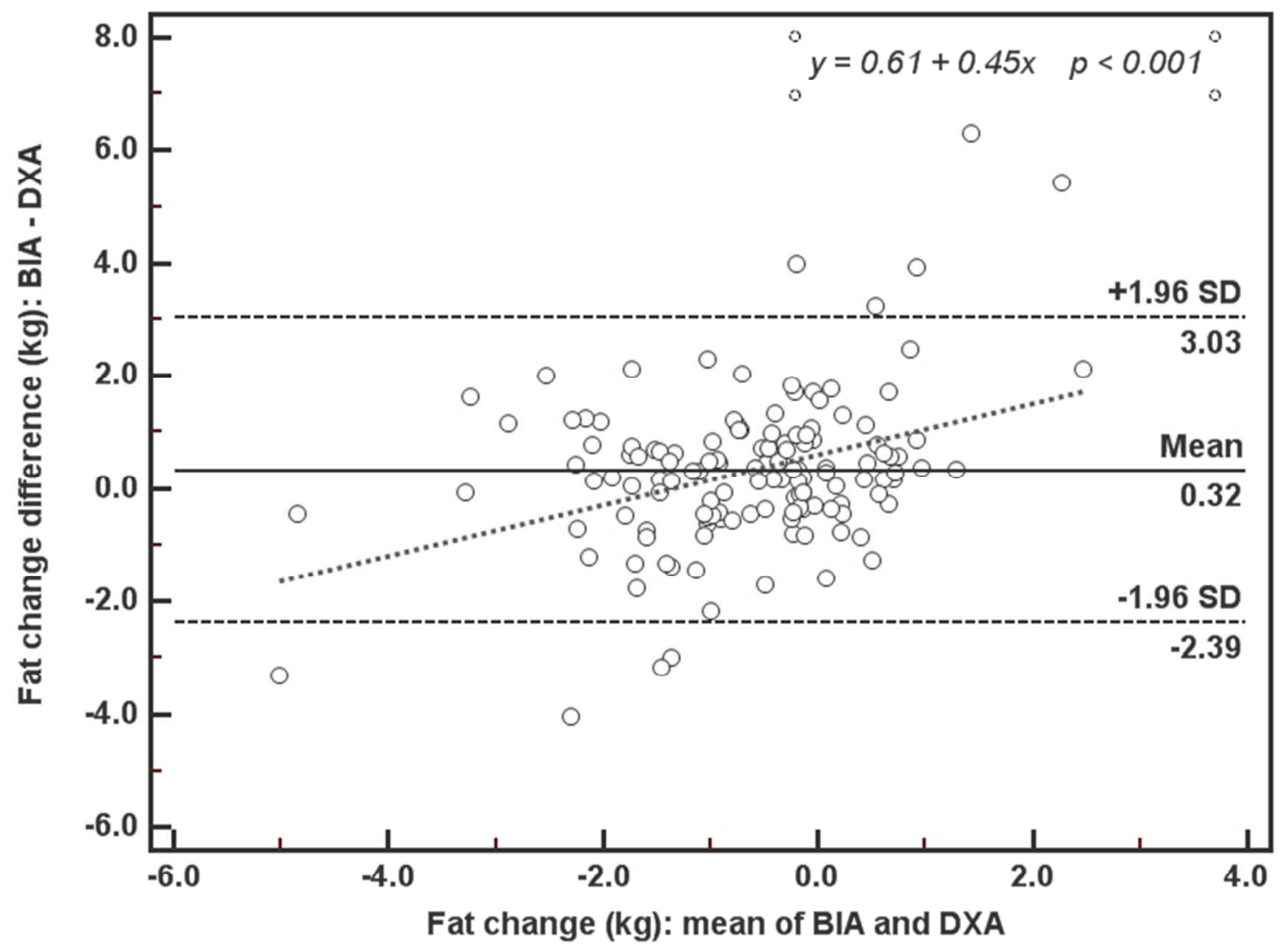

URL: http://mc.manuscriptcentral.com/rjsp 
Figure 2. Bland-Altman plot of lean tissue change-score comparing the mean of Dual-energy X-ray absorptiometry (DXA) and Bioelectrical Impedance Analysis (BIA) against the difference between BIA and DXA.

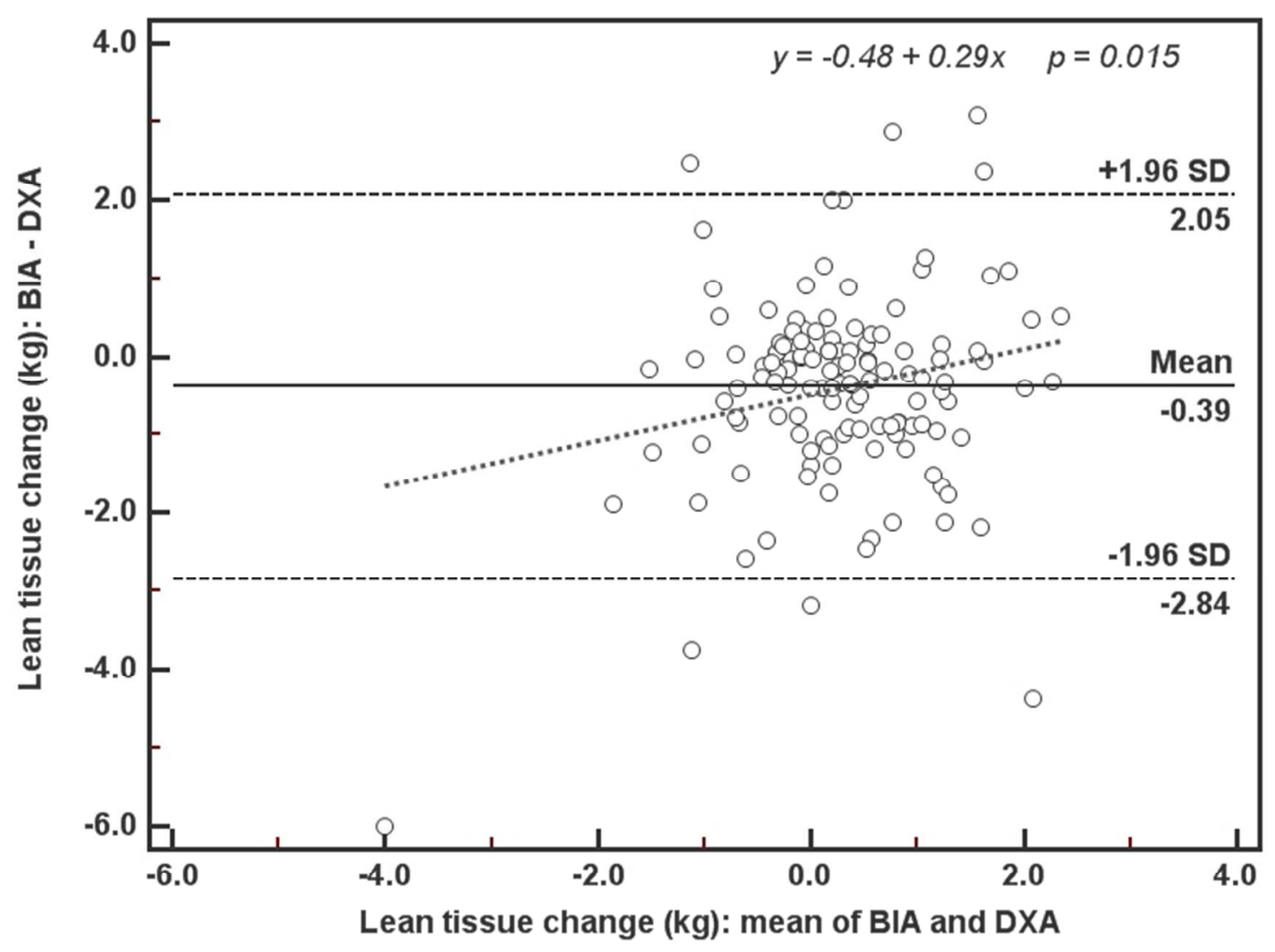

URL: http://mc.manuscriptcentral.com/rjsp 
Table 1. Participant information showing means \pm SD or $n(\%),(B M I=$ body mass index).

\begin{tabular}{|l|l|l|l|}
\hline & Male $(\mathrm{n}=42)$ & Female $(\mathrm{n}=94)$ & Total $(\mathrm{n}=136)$ \\
\hline Age $(\mathrm{yrs})$ & $45.1 \pm 13.9$ & $43.3 \pm 11.0$ & $44.2 \pm 12.0$ \\
\hline Stature $(\mathrm{m})$ & $1.71 \pm 0.07$ & $1.59 \pm 0.07$ & $1.63 \pm 0.09$ \\
\hline Mass $(\mathrm{kg})$ & $77.4 \pm 12.0$ & $60.3 \pm 11.0$ & $65.3 \pm 13.6$ \\
\hline BMI $\left(\mathrm{kg} / \mathrm{m}^{2}\right)$ & $26.3 \pm 3.3$ & $23.5 \pm 3.6$ & $24.3 \pm 3.7$ \\
\hline Overweight $\geq 25$ BMI & $23(55 \%)$ & $22(23 \%)$ & $45(33 \%)$ \\
\hline Obese $\geq 30$ BMI & $6(14 \%)$ & $4(4 \%)$ & $10(7 \%)$ \\
\hline Between tests (days) & $74.2 \pm 17.3$ & $74.2 \pm 18.3$ & $74.2 \pm 17.9$ \\
\hline
\end{tabular}


Table 2. Baseline, post-intervention, change-score data and statistics for BIA and DXA measurements, as well as comparisons of changescores (delta) between devices: means \pm SD.

\begin{tabular}{|c|c|c|c|c|c|c|c|}
\hline & Baseline, $\mathrm{Kg}$ & $\begin{array}{c}\text { Post- } \\
\text { intervention, } \\
\mathrm{Kg}\end{array}$ & $\begin{array}{c}\text { Change-score, } \\
\mathrm{Kg},(\%)\end{array}$ & $\begin{array}{c}\text { Change-score } \\
\text { LOA }\end{array}$ & $\begin{array}{c}\text { Change-score: } \\
\text { p-value } \\
\text { (t-test) }\end{array}$ & $\begin{array}{l}\text { Change-score: } \\
\text { Effect size, d }\end{array}$ & $\begin{array}{c}\text { Correlation, } r \\
\text { (p-value) }\end{array}$ \\
\hline Weight (Kg) & $\begin{array}{c}65.287 \pm \\
13.603 \\
\end{array}$ & $\begin{array}{c}64.975 \pm \\
13.351 \\
\end{array}$ & $\begin{array}{c}-0.313 \pm 1.500 \\
(-0.5 \%)\end{array}$ & $-3.25-2.63$ & 0.008 & $\begin{array}{c}0.20 \\
\text { (small) }\end{array}$ & \\
\hline Fat DXA (Kg) & $\begin{array}{c}21.981 \pm \\
6.589\end{array}$ & $\begin{array}{c}21.179 \pm \\
6.197\end{array}$ & $\begin{array}{c}-0.802 \pm 1.092 \\
(-3.6 \%)\end{array}$ & $-2.95-1.35$ & $<0.001$ & $\begin{array}{c}0.16 \\
\text { (small) }\end{array}$ & \\
\hline Fat BIA (Kg) & $\begin{array}{c}19.554 \pm \\
6.898^{* *}\end{array}$ & $\begin{array}{c}19.068 \pm \\
6.827\end{array}$ & $\begin{array}{c}-0.486 \pm 1.539 \\
(-2.5 \%)\end{array}$ & $-3.50-2.53$ & $<0.001$ & $\begin{array}{c}0.17 \\
\text { (small) }\end{array}$ & \\
\hline $\begin{array}{c}\text { delta-Fat } \\
\text { (DXA v BIA) }\end{array}$ & & & & & 0.003 & $\begin{array}{c}0.72 \\
\text { (large) }\end{array}$ & $\begin{array}{c}0.511 \\
(<0.001)\end{array}$ \\
\hline $\begin{array}{c}\text { Lean DXA } \\
(\mathrm{Kg})\end{array}$ & $\begin{array}{c}42.561 \pm \\
9.485 \\
\end{array}$ & $\begin{array}{c}43.039 \pm \\
9.663 \\
\end{array}$ & $\begin{array}{c}0.477 \pm 0.966 \\
(+1.1 \%)\end{array}$ & $-1.42-2.37$ & $<0.001$ & $\begin{array}{c}0.09 \\
\text { (trivial) }\end{array}$ & \\
\hline Lean BIA (Kg) & $\begin{array}{l}43.255 \pm \\
9.967^{* *}\end{array}$ & $\begin{array}{c}43.339 \pm \\
9.908\end{array}$ & $\begin{array}{c}0.084 \pm 1.201 \\
(+0.2 \%)\end{array}$ & $-2.27-2.44$ & 0.425 & $\begin{array}{c}0.08 \\
\text { (trivial) }\end{array}$ & \\
\hline $\begin{array}{c}\text { delta-Lean } \\
\text { (DXA v BIA) }\end{array}$ & & & & & $<0.001$ & $\begin{array}{c}0.79 \\
\text { (large) }\end{array}$ & $\begin{array}{c}0.362 \\
(<0.001)\end{array}$ \\
\hline $\begin{array}{c}\text { Bone DXA } \\
(\mathrm{Kg})\end{array}$ & $\begin{array}{c}2.143 \pm \\
0.392\end{array}$ & $\begin{array}{c}2.150 \pm \\
0.388\end{array}$ & $\begin{array}{c}0.007 \pm 0.041 \\
(+0.3 \%)\end{array}$ & $-0.07-0.09$ & 0.052 & $\begin{array}{c}0.08 \\
\text { (trivial) }\end{array}$ & \\
\hline $\begin{array}{c}\text { Bone BIA } \\
\text { (Kg) }\end{array}$ & $\begin{array}{l}2.543 \pm \\
0.496^{* *}\end{array}$ & $\begin{array}{c}2.557 \pm \\
0.496\end{array}$ & $\begin{array}{c}0.014 \pm 0.091 \\
(+0.6 \%)\end{array}$ & $-0.16-0.19$ & 0.074 & $\begin{array}{c}0.11 \\
\text { (trivial) }\end{array}$ & \\
\hline $\begin{array}{l}\text { delta-Bone } \\
\text { (DXA v BIA) }\end{array}$ & & & & & 0.392 & $\begin{array}{c}0.93 \\
\text { (large) }\end{array}$ & $\begin{array}{c}0.172 \\
(0.047)\end{array}$ \\
\hline
\end{tabular}

BIA = bioelectrical impedance analysis; DXA = dual-energy X-ray absorptiometry; LOA = limits of agreement; ${ }^{* *}=\mathrm{BIA}$ and DXA values at Baseline were significantly different (t-test: $\mathrm{p}<0.01$ ) 